\title{
RELATIONSHIP BETWEEN PERSON-ORGANIZATION FIT AND OBJECTIVE AND SUBJECTIVE HEALTH STATUS (PERSON-ORGANIZATION FIT AND HEALTH)
}

\section{DOROTA MERECZ and ALEKSANDRA ANDYSZ}

Nofer Institute of Occupational Medicine, Łódź, Poland

Work Psychology Department

\begin{abstract}
Objectve: Person-Environment fit (P-E fit) paradigm, seems to be especially useful in explaining phenomena related to work attitudes and occupational health. The study explores the relationship between a specific facet of P-E fit as PersonOrganization fit (P-O fit) and health. Materials and Methods: Research was conducted on the random sample of $600 \mathrm{em}-$ ployees. Person-Organization Fit Questionnaire was used to asses the level of Person-Organization fit; mental health status was measured by General Health Questionnaire (GHQ-28); and items from Work Ability Index allowed for evaluation of somatic health. Data was analyzed using non parametric statistical tests. The predictive value of P-O fit for various aspects of health was checked by means of linear regression models. Results: A comparison between the groups distinguished on the basis of their somatic and mental health indicators showed significant differences in the level of overall P-O fit $(\chi 2=23.178 ; p<0.001)$ and its subdimensions: for complementary fit $\left(\chi^{2}=29.272 ; p<0.001\right)$, supplementary fit $(\chi 2=23.059 ; p<0.001)$, and identification with organization $(\chi 2=8.688 ; p=0.034)$. From the perspective of mental health, supplementary P-O fit seems to be important for men's well-being and explains almost $9 \%$ of variance in GHQ-28 scores, while in women, complementary fit (5\% explained variance in women's GHQ score) and identification with organization (1\% explained variance in GHQ score) are significant predictors of mental well-being. Interestingly, better supplementary and complementary fit are related to better mental health, but stronger identification with organization in women produces adverse effect on their mental health. Conclusions: The results show that obtaining the optimal level of P-O fit can be beneficial not only for the organization (e.g. lower turnover, better work effectiveness and commitment), but also for the employees themselves. Optimal level of P-O fit can be considered as a factor maintaining workers' health. However, prospective research is needed to confirm the results obtained in this exploratory study.
\end{abstract}

Key words:

Supplementary, Complementary person-organization fit, Identification with organization, Health

\section{INTRODUCTION}

Interactions between a human and his/her work environment is still a very popular stream of research in psychology. Numerous classical theories have been established within this area of research, including Theory of Career Choice [1], Person-Environment-Fit Theory [2] or Theory of Work Adjustment [3]. They are all an attempt of scientific explanation, firstly concerned with what it means to be "the right man at the right place" at work; secondly, what the obstacles in finding one's place within work environment are; and thirdly, what the consequences of person-work environment fit vs. misfit are.

Analyses of various aspects of Person-Environment fit (P-Efit) (person-job fit, person-group fit, person-supervisor

Received: January 11, 2012. Accepted: February 22, 2012.

Address reprint request to D. Merecz, Work Psychology Department, Nofer Institute of Occupational Medicine, św. Teresy 8, 91-348 Łódź, Poland (e-mail: merecz@imp.lodz.pl). 
fit and person-organization fit) suggest that the optimum level of fit is an important factor in maintaining workers' health, work ability and quality of life. Numerous studies confirm the significant relation between the level of person-environment fit and various work attitudes such as: job satisfaction, job commitment, intention to quit or turnover [4-7], but surprisingly little attention is devoted to the relationship between the level of person-work environment fit and health. Studies on direct relationship between person - work environment fit and employees' health are sparse, but bring interesting results. Misfit between an employee and his/her work environment results in elevated job stress [8,9], depression [10], anxiety [10,11], burnout [11] or decreased ability to take up physical and mental effort at work [12].

In this paper, the authors examine a relationship between one of the aspects of person-work environment fit which is called Person-Organization fit (P-O fit) and health P-O fit is defined by Kristof [13] as "the compatibility between people and organizations that occurs when: (a) at least one entity provides what the other needs, or (b) they share similar fundamental characteristics, or (c) both" (p. 4-5). Those fundamental characteristics are, for example: goal congruence, value congruence, needs-structure fit or personality-climate fit [4]. The majority of the research focus on the values as the basic dimension of P-O fit $[4,13,14]$. There are two types of relationships between workers and their organizations: complementary and supplementary fit [14]. Complementary P-O fit is understood as the extent to which organization meets the expectations of an employee and the extent to which an employee is able to meet the demands of the organization. It can be also understood as the extent to which "weaknesses or needs of the environment are offset by strengths of the individual, and vice versa" [15, p. 271]. Supplementary P-O fit exists when a person and organization possess similar characteristics. The most often, it is understood as goals and values congruence [13].
Some researchers and theoreticians distinguish one more dimension of P-O fit, i.e. identification with the organization. It is defined as the extent to which an individual identifies with the organization as a social group [16-21]. According to social identity theory, organizational identification is a form of social identification. Through a cognitive process of categorization, individual forms self-categories of organizational membership. Identification with organization exists when two criteria are met: (a) individual's identification with organization is stronger than identification with other social groups (e.g. other potential employers); (b) individual's self-schema includes many of the attributes which one accredits to the organization [20]. Although there are voices suggesting that identification with organization is a form of organizational commitment or distinctive construct from the concept of fit [22,23], we believe that organizational identification may be treated as a form of P-O fit. The person who identifies him/herself with the organization, according to the afore-mentioned definition shares the same characteristics with the organization perceived as a social system. Hence, identification with organization is rooted in similarity between an employee and employing organization.

\section{OBJECTIVE}

The aim of the study was to determine the relationship between various aspects of Person-Organization fit and health outcome. Although the person-organization fit phenomenon is intensively studied, little attention is paid to its direct relation to employees' health. One can observe the gap between two streams of research - in the first one, grounded in person-environment fit stress theories, a lot of effort is invested in determining the relationships between P-E fit and health outcome, while in the second stream of research, focused on specific organization or job-based dimensions of fit (person-organization, person-job or person-group fit), this problem is consistently 
disregarded. Taking into account the fact that P-O fit is a specific facet of the boarder P-E fit construct it is justifiable to think that poor P-O fit via stress process may lead to poor-ill health.

It is well-known that P-O misfit results in decreased work satisfaction, intention to quit the job and it affects organization citizenship behaviors. However, there is a lack of comprehensive data on this subject. To support theoretical considerations we conducted a research on the relationship between complementary and supplementary P-O fit, as well as the strength of social identification with organization and health status. We assume that all the analyzed facets of P-O fit are positively related to the health of employees, which will be reflected in the indices of the mental and somatic health status. The employees with poor ill-health will be characterized by a significantly lower level of P-O fit - both the general and specific one. The open question is, which out of the three facets of P-O fit: complementary, supplementary and the strength of social identification with organization is the best predictor of employees' health. We also assume that, in comparison to the somatic health status, the metal health status will be an especially sensitive indicator of poor P-O fit.

\section{MATERIALS AND METHODS}

\section{Participants}

A nation-wide sample of 600 employees, city dwellers aged from 19 to 65 years was gathered. The sample was representative for occupationally active population of Polish citizens in terms of gender, age, size of inhabited city. In the sampling procedure the following exclusion criteria were employed: being on parental leave, receiving disability payment or pension; being a full-time student. The respondents represented various occupations from each of the main categories taken from the Polish Classification of Occupations and Specializations for Labor Market Needs. The data was collected at the respondents' home in
December 2010. Women accounted for $52.5 \%$ of the group, men $-47.5 \%$. The mean age was $39.48(\mathrm{SD}=11.04)$. The mean overall tenure was $17,38(\mathrm{SD}=11.24)$ and mean tenure at the current position was $9.53(9.44)$.

\section{Measurement}

The variables were measured by means of the following questionnaires:

Person-Organization Fit Questionnaire - a subjective measure of fit by Czarnota-Bojarska [24] was used to assess the three dimensions of P-O fit. It is a 50-item tool allowing for the diagnosis of the level of supplementary and complementary fit and employee's identification with organization. The higher is the score obtained in all three subscales the better is P-O fit.

General Health Questionnaire (GHQ-28) by Goldberg and Williams [25] - a widely used screening instrument for psychological disturbances in the general population. It assesses the respondent's current mental health status. GHQ-28 consists of 4 subscales: somatic symptoms (GHQ-A), anxiety and insomnia (GHQ-B), social dysfunction (GHQ-C) and severe depression (GHQ-D). A high score in GHQ-28 serves as the indicator of poor mental health. For the purpose of this paper only general GHQ-28 score was calculated. Psychometric properties of the Polish adaptation of GHQ-28 are satisfactory and comparable to the original ones [25]. Items from the Work Ability Index [26] in the Polish adaptation by Pokorski [27] including: screening list for the presence of somatic diseases diagnosed by a doctor, but reported by the respondents themselves, self-assessment of one's own health status.

The number of medically diagnosed somatic diseases declared by the respondents together the with GHQ-28 total score served as 'objective' indicators of the health status, while the answer to the question: 'How do you estimate your current health status compared with others at your age?' on a 5-point answer scale (from very good to very 
bad) was used as a relative subjective indicator of the current health status.

\section{Statistical analysis}

Statistical analysis was performed with the help of SPSS.18 for Windows. Nonparametric tests Kruskal-Wallis, oneway analysis of variance and Mann-Whitney test in pairwise comparisons were calculated to check if there are differences in P-O fit among the groups of the respondents with different health status. Linear regression analysis was performed to check the predictive value of the three aspect of $\mathrm{P}-\mathrm{O}$ fit in order to establish the health status.

\section{RESULTS}

Descriptive statistics for health indicators in the study sample are shown in Table 1.

On average, the respondents in comparison to other people at the same age, subjectively assessed their actual health as good. This result is consistent with the data on the number of somatic diseases diagnosed by a doctor (see Table 1), and mental health status assessed by GHQ-28. Mean score of GHQ-28, according to Polish norms for working population developed by Makowska and Merecz [25], reached the level of 5th sten, what means that the subjects' mental health status was moderate. Most of the respondents were somatically healthy $(57.2 \%), 22.2 \%$ suffered from one somatic disease, $11.8 \%$ from two diseases and $8.9 \%$ were diagnosed with three or more somatic diseases. The most common somatic diseases in the study population were: musculoskeletal disorders (18.7\%), cardiovascular disorders (13.4\%), respiratory diseases $(10.5 \%)$ and gastrointestinal diseases $(9.0 \%)$. To compare the level of P-O fit depending on the health status, subjects under the study were divided into four groups. The first criterion of the division was: two objective indicators of the respondents' health status (GHQ score and number of diseases).

The first group (somatic+/mental+) consisted of individuals with low or mean scores in GHQ-28 and without any diagnosed somatic disease ( $52.5 \%$ of the sample). The second group (somatic-/mental+) consisted of individuals with low or mean scores in GHQ-28, and with at least one diagnosed somatic disease - it was considered that these are people who, despite physical ailments, feel mentally good (34.7\%). The third group (somatic-/mental-) consisted of the respondents with high GHQ-28 scores and diagnosed with at least one somatic illness - in other words these were people suffering from both physical and mental ailments $(8.7 \%)$. The fourth group (somatic+/mental-) consisted of individuals highly scored in GHQ-28 without any diagnosed somatic disease (4.2\%).

The second criterion of division was self-assessment of general health in comparison with other people at the same age. The majority of the respondents identified their current health status as good (52\%), the second largest group consisted of the respondents defining their actual health as very good (24\%), then moderate $(20.2 \%)$. No one considered his or her health as very bad.

The results of one-way analysis of variance and pairwise comparison between the groups distinguished on the

Table 1. Descriptive statistics of health indicators in a research group $(\mathrm{N}=600)$

\begin{tabular}{lccc}
\hline Health indicators & Subjective assessment of health & $\begin{array}{c}\text { Diagnosed diseases } \\
(\mathrm{n})\end{array}$ & $\begin{array}{c}\text { Mental health status } \\
\text { (GHQ-28 general score) }\end{array}$ \\
\hline Min & 1 & 0 & 1 \\
Max & 4 & 7 & 70 \\
Mean & 2.0 & 0.8 & 18.6 \\
Standard deviation & 0.8 & 1.1 & 9.0 \\
\hline
\end{tabular}




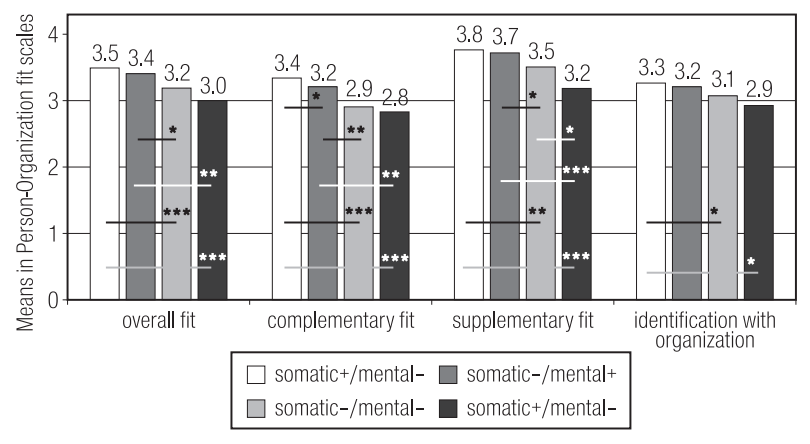

Significance level: ${ }^{*} \mathrm{p}<0.05,{ }^{* *} \mathrm{p}<0.01,{ }^{* * *} \mathrm{p}<0.001$.

Fig. 1. Differences in the levels of overall P-O fit and its aspects between the groups of different objective health status

base of the respondents' objective health status showed significant differences in the level of $\mathrm{P}-\mathrm{O}$ fit. These differences were observed both for P-O fit general score $(\chi 2(3, \mathrm{~N}=600)=23.178 ; \mathrm{p}<0.001)$ and sub-dimensions of P-O fit: for complementary fit $(\chi 2(3, \mathrm{~N}=600)=29.272$; $\mathrm{p}<0,001)$, supplementary fit $(\chi 2(3, \mathrm{~N}=600)=23.059$; $\mathrm{p}<0.001)$, and identification with organization $(\chi 2(3, N=600)=8.688 ; p=0.034)$. The results of pairwise comparison are shown on Figure 1 and described below.

As regards the level of overall P-O fit, people somatically and mentally healthy differed significantly from the people somatically ill, but mentally healthy, and from people both somatically and mentally ill - they obtained significantly higher score of overall P-O fit. The group of people somatically ill and mentally healthy significantly differed from the people somatically ill but mentally healthy, and from people both somatically and mentally ill. There were no significant differences between the groups of healthy individuals and people somatically ill but mentally healthy. There were also no differences between the people somatically ill and those physically healthy, but having mental health problems. One can say that the level of overall P-O fit shaped significant differences in mental health - people who reached a higher level of overall P-O fit, were psychologically healthier, regardless of the somatic health status, while those who received lower scores on the scale of overall P-O fit were also the ones whose mental health was also significantly worse. The overall level of P-O fit significantly differentiated individuals objectively in terms of their mental health, thus one can say that a decrease in the level of overall P-O fit may result in deterioration of the mental health status.

Complementary P-O fit very clearly differentiated most of the groups in terms of objective health. Only two groups did not differ significantly - the group of people both somatically and mentally ill and the group of people somatically healthy but having mental problems. These two groups have in common the fact of experiencing mental health problems. The remaining groups differed significantly between each other. Regardless of the state of somatic health, mental health deterioration characterized people who obtained the lowest scores in complementary P-O fit. The higher was the level of complementary P-O fit, the better was the mental health state of subjects.

As regards supplementary P-O fit, people physically and mentally healthy did not differ significantly from the people physically ill but mentally healthy and had the highest scores on this scale. Surprisingly, people physically and mentally ill obtained a significantly higher level of supplementary Person-Organization fit than the ones having mental problems but being physically healthy. The level of supplementary P-O fit differentiated the groups the most among one another, therefore it can be concluded that this aspect of P-O fit, among the others measured aspects, is associated the most with the objective health status. Thus, low supplementary P-O fit may result both in deterioration of somatic and mental health.

The smallest number of differences between the distinguished groups was found as for identification with organization. Only the totally healthy respondents differed significantly from the group with mental health problems and the group of somatically and mentally ill persons. 


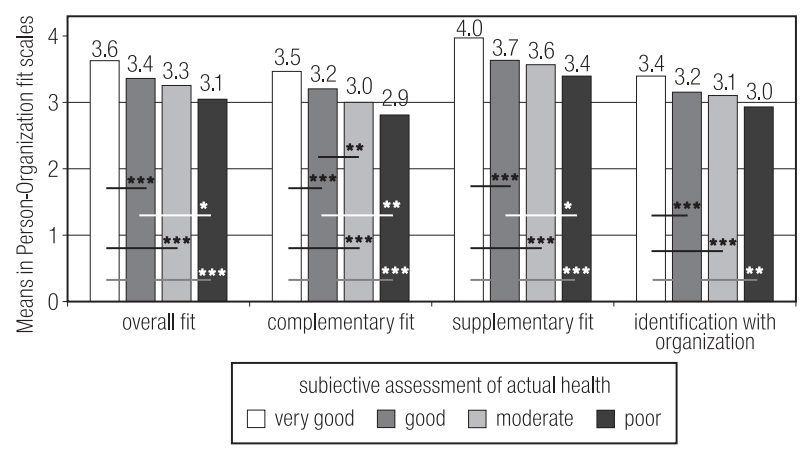

Significance level: * $\mathrm{p}<0.05 ;{ }^{* *} \mathrm{p}<0.01 ;{ }^{* * *} \mathrm{p}<0.001$.

Fig. 2. Differences in the levels of overall P-O fit and its aspects between groups of different subjective health status

The subjective assessment of one's own health also differentiated the level of P-O fit. Kruskal-Wallis test showed that the subjective health status varies significantly as regards the level of the general Person-Organization fit score $(\chi 2(3, \mathrm{~N}=600)=35.092 ; \mathrm{p}<0.001)$ and in each of its three dimensions (complementary fit $(\chi 2(3, \mathrm{~N}=600)=32.441 ; \mathrm{p}<0,001)$, supplementary fit $(\chi 2(3, \mathrm{~N}=600)=38.722 ; \mathrm{p}<0.001)$ and identification with organization $(\chi 2(3, \mathrm{~N}=600)=19.188 ; \mathrm{p}<0.001$. The results of pairwise comparison are shown on Figure 2, and described below.

The highest scores on the scale of overall P-O fit were obtained by persons who assessed their actual health status as very good. There was no significant difference in P-O fit between individuals who evaluated their actual health status as good and those who evaluated it as moderate. The groups with moderate and poor health also did not differ significantly between each other. Both these groups received the lowest scores of overall P-O fit. In the case of complementary P-O fit, only individuals who consider their actual health as moderate and poor did not differ from each other. One can find the observable decreasing tendency in the level of complementary fit along with worsening of the subjective assessment of the health status. A similar pattern of results was found for supplementary P-O fit. Individuals evaluating their health as very good significantly differed from those who assessed it as good, moderate and poor as regards supplementary P-O fit. Their scores were significantly higher than the scores of other groups. People with good subjective health differed significantly from those with poor health in terms of supplementary fit, but there was no significant difference between the people evaluating their health status as moderate and poor.

The smallest number of inter-group differences was found as for identification with organization. Only individuals evaluating their health as very good significantly differed from all others groups.

To find out which of the three dimensions of P-O fit is the best predictor of health, several regression analyses were performed in two stages, separately for three health indicators, which were: subjective health status (based on selfassessment of one's own health in comparison to other people at the same age), mental health status (indicated by GHQ-28 score) and number of diagnosed somatic diseases. The analyses were performed separately for males and females. In the first stage, when only dimensions of fit were included into the models as the explaining variables, almost all aspects of P-O fit turned out to be significant predictors of health (Tables 2-4). The exception is women's somatic health measured by the number of somatic diseases they suffered from. In this case, none of the aspects of P-O fit was a significant predictor of women's somatic health.

In the second stage of analysis, other health risk factors, i.e. age and the level of family stress were controlled for in the regression models. On one hand, it improved the statistics of the tested models, and it allowed to select the strongest predictors of health status on the other (Tables 5-7).

The first observable difference in both kinds of regression models concerns the different contribution of P-O fit dimensions in explaining the mental and subjective health status of women and men. From the perspective of mental 
Table 2. Regression analysis results for the mental health status

\begin{tabular}{lccccccc}
\hline $\begin{array}{c}\text { Predictors of the mental } \\
\text { health status }\end{array}$ & Adjusted $\mathrm{r}^{2}$ & $\begin{array}{c}\text { Std. Error of } \\
\text { the estimate }\end{array}$ & $\mathrm{R}^{2}$ change & $\begin{array}{c}\text { Significance } \\
\text { change }\end{array}$ & $\mathrm{B}$ & Std. Error & $\beta$ \\
\hline $\begin{array}{l}\text { Males } \\
\quad \text { complementary fit }\end{array}$ & 0.122 & 7.091 & 0.125 & 0.000 & -2.131 & 0.945 & -0.203 \\
$\quad \begin{array}{l}\text { supplementary fit } \\
\text { Females }\end{array}$ & 0.133 & 7.048 & 0.014 & 0.035 & -2.516 & 1.189 & -0.191 \\
$\quad \begin{array}{l}\text { supplementary fit } \\
\text { identification with } \\
\text { organization }\end{array}$ & 0.076 & 9.655 & 0.079 & 0.000 & -3.861 & 1.335 & -0.287 \\
$\quad$ supplementary fit & 0.095 & 9.555 & 0.022 & 0.006 & -5.597 & 1.553 & -0.330 \\
\hline
\end{tabular}

$\mathrm{R}^{2}$ - coefficient of determination.

Std. - standard.

B - unstandardized regression coefficient.

$\beta$-standardized regression coefficient.

Table 3. Regression analysis results for the subjective health status

\begin{tabular}{lccccccc}
\hline $\begin{array}{c}\text { Predictors of the } \\
\text { subjective health status }\end{array}$ & Adjusted $\mathrm{r}^{2}$ & $\begin{array}{c}\text { Std. Error of } \\
\text { the estimate }\end{array}$ & $\mathrm{R}^{2}$ change & $\begin{array}{c}\text { Significance } \\
\text { change }\end{array}$ & $\mathrm{B}$ & Std. Error & $\beta$ \\
\hline $\begin{array}{l}\text { Males } \\
\text { complementary fit }\end{array}$ & 0.044 & 0.741 & 0.047 & 0.000 & -0.228 & 0.061 & -0.217 \\
$\begin{array}{l}\text { Females } \\
\text { supplementary fit }\end{array}$ & 0.083 & 0.749 & 0.086 & 0.000 & -0.387 & 0.071 & -0.293 \\
\hline
\end{tabular}

Abbreviations as in Table 2.

Table 4. Regression analysis results for the number of diagnosed somatic diseases

\begin{tabular}{lccccccc}
\hline $\begin{array}{c}\text { Predictors of the } \\
\text { number of diagnosed } \\
\text { somatic diseases }\end{array}$ & Adjusted $\mathrm{r}^{2}$ & $\begin{array}{c}\text { Std. Error } \\
\text { of the estimate }\end{array}$ & $\mathrm{R}^{2}$ change & $\begin{array}{c}\text { Significance } \\
\text { of F change }\end{array}$ & B & Std. Error & $\beta$ \\
\hline $\begin{array}{c}\text { Males } \\
\text { complementary fit }\end{array}$ & 0.014 & 0.990 & 0.018 & $\mathrm{p}=0.025$ & -0.184 & 0.081 & -0.133 \\
\hline
\end{tabular}

Abbreviations as in Table 2.

health, supplementary P-O fit seems to be important for men's well-being and explains almost $9 \%$ of the variance in GHQ-28 scores, while in women, complementary fit (5\% explained variance in women's GHQ score) and identification with organization (1\% explained variance in GHQ score) are significant predictors of mental well-being.
Interestingly, supplementary and complementary fit are related to better mental health, but stronger identification with organization in women produces adverse effect on their mental health.

As for the subjective assessment of health in relation to complementary and supplementary P-O fit, the pattern of 
Table 5. Regression analysis results for the mental health status

\begin{tabular}{|c|c|c|c|c|c|c|c|}
\hline $\begin{array}{l}\text { Predictors of the mental } \\
\text { health status }\end{array}$ & Adjusted $r^{2}$ & $\begin{array}{c}\text { Std. Error } \\
\text { of the estimate }\end{array}$ & $\mathrm{R}^{2}$ change & $\begin{array}{l}\text { Significance } \\
\text { of } F \text { change }\end{array}$ & B & Std. Error & $\beta$ \\
\hline \multicolumn{8}{|l|}{ Males } \\
\hline family stress & 0.202 & 6.760 & 0.205 & $\mathrm{p}<0.001$ & 1.216 & 0.155 & 0.393 \\
\hline supplementary fit & 0.288 & 6.388 & 0.088 & $\mathrm{p}<0.001$ & -4.048 & 0.656 & -0.307 \\
\hline age & 0.310 & 6.286 & 0.025 & $\mathrm{p}=0.002$ & 0.109 & 0.034 & 0.159 \\
\hline \multicolumn{8}{|c|}{ excluded variables: complementary fit, identification with organization } \\
\hline \multicolumn{8}{|l|}{ Females } \\
\hline family stress & 0.260 & 8.623 & 0.262 & $\mathrm{p}<0.001$ & 1.806 & 0.173 & 0.489 \\
\hline complementary fit & 0.308 & 8.339 & 0.050 & $\mathrm{p}<0.001$ & -5.016 & 1.043 & -0.374 \\
\hline $\begin{array}{l}\text { identification with } \\
\text { organization }\end{array}$ & 0.318 & 8.275 & 0.013 & $\mathrm{p}=0.016$ & 2.449 & 1.014 & 0.188 \\
\hline excluded variables: sup & plementary & , age & & & & & \\
\hline
\end{tabular}

Abbreviations as in Table 2.

Table 6. Regression analysis results for the subjective health status

\begin{tabular}{|c|c|c|c|c|c|c|c|}
\hline $\begin{array}{l}\text { Predictors of the } \\
\text { subjective/actual } \\
\text { health status }\end{array}$ & Adjusted $r^{2}$ & $\begin{array}{l}\text { Std. Error of } \\
\text { the estimate }\end{array}$ & $\mathrm{R}^{2}$ change & $\begin{array}{l}\text { Significance of } \\
\text { F change }\end{array}$ & B & Std. Error & $\beta$ \\
\hline \multicolumn{8}{|l|}{ Males } \\
\hline age & 0.116 & 0.712 & 0.119 & $\mathrm{p}<0.001$ & 0.022 & 0.004 & 0.315 \\
\hline family stress & 0.169 & 0.691 & 0.056 & $\mathrm{p}<0.001$ & 0.066 & 0.017 & 0.212 \\
\hline complementary fit & 0.200 & 0.678 & 0.033 & $\mathrm{p}=0.001$ & -0.193 & 0.056 & -0.184 \\
\hline \multicolumn{8}{|c|}{ excluded variables: supplementary fit, identification with organization } \\
\hline \multicolumn{8}{|l|}{ Females } \\
\hline supplementary fit & 0.083 & 0.750 & 0.086 & $\mathrm{p}<0.001$ & -0.412 & 0.068 & -0.312 \\
\hline age & 0.184 & 0.708 & 0.104 & $\mathrm{p}<0.001$ & 0.022 & 0.004 & 0.311 \\
\hline family stress & 0.221 & 0.692 & 0.039 & $\mathrm{p}<0.001$ & 0.058 & 0.015 & 0.200 \\
\hline
\end{tabular}

Abbreviations as in Table 2.

relationship is quite the opposite. Men's self-evaluation of their own health is predicted by their subjective complementary fit, while supplementary fit serves as the predictor of self-evaluation of health in women (Table 6). Both supplementary and complementary fit are positively related to subjective assessment of the general health status.
In case of the number of diagnosed somatic diseases, the results of regression analyses for men and women were more coherent. Regardless of the gender, complementary P-O fit was a significant, though weak, predictor of the value of that health indicator (Table 7). It accounts only for $1.8 \%$ of the variance in the number of diagnosed 
Table 7. Regression analysis for the number of diagnosed diseases

\begin{tabular}{|c|c|c|c|c|c|c|c|}
\hline $\begin{array}{c}\text { Predictors of the } \\
\text { number of diagnosed } \\
\text { diseases }\end{array}$ & Adjusted $r^{2}$ & $\begin{array}{l}\text { Std. Error of } \\
\text { the estimate }\end{array}$ & $\mathrm{R}^{2}$ change & $\begin{array}{l}\text { Significance of } \\
\text { F change }\end{array}$ & B & Std. Error & $\beta$ \\
\hline \multicolumn{8}{|l|}{ Males } \\
\hline age & 0.096 & 1.023 & 0.099 & $\mathrm{p}<0.001$ & 0.031 & 0.005 & 0.314 \\
\hline complementary fit & 0.111 & 1.014 & 0.018 & $\mathrm{p}=0.016$ & -0.203 & 0.083 & -0.136 \\
\hline \multicolumn{8}{|c|}{ excluded. variables: supplementary fit, identification with organization. family stress } \\
\hline \multicolumn{8}{|l|}{ Females } \\
\hline age & 0.070 & 1.331 & 0.073 & $\mathrm{p}<0.001$ & 0.035 & 0.007 & 0.281 \\
\hline family stress & 0.094 & 1.314 & 0.028 & $p=0.002$ & 0.080 & 0.027 & 0.157 \\
\hline complementary fit & 0.106 & 1.305 & 0.014 & $p=0.027$ & -0.222 & 0.100 & -0.120 \\
\hline
\end{tabular}

Abbreviations as in Table 2.

diseases in men and $1.4 \%$ of this variance in women. In the light of the obtained results, the better complementary fit, the better somatic health of the respondents.

\section{DISCUSSION}

Researchers interested in the field of work and organizational psychology fix their attention mainly on the relationship between P-O fit and organizational outcomes such as: turnover, intention to quit the job, work effectiveness, quality of service, job satisfaction and commitment, ignoring almost completely other possible effects of $\mathrm{P}-\mathrm{O}$ fit versus misfit [5,28]. The issue of workers' health in relation to P-O fit is almost not studied. However, taking into account that P-O fit is located within the boarder framework of person-environment fit, the goodness of congruence between an employee and the employing organization can serve as a predictor of psychological strain and health outcome. The positive relation between P-O fit and the health outcome is expected, based on theoretical considerations [e.g. 13,29] and empirical findings within P-E fit paradigm [e.g. 5,7,30-32].

The results of the presented study show, that the relationship between P-O fit and health outcome does exist. Generally speaking, poorer health status is related to lower level of P-O fit. Mental health seems to be particularly important in this relationship. Employees who scored high in GHQ28 (with poorer mental health status) were less congruent with their work environment than those who mentally felt good or suffered only from somatic disease. This difference was stable across various subdimensions of P-O fit. Of course, the cause-effect interpretation of the results is not possible due to cross-sectional format of the study, but according to P-E fit theory, lack of adjustment resulting from poor congruence between a person and the environment is a source of chronic psychological strain. If so, P-O misfit should have the same effect on workers well-being. This hypothesis was verified with the help of linear regression analysis performed separately for men and women with controlling for two additional variables: age and perceived family stress (measured with one question "How stressful is your family life?" with a 10-point response scale, from 0 - not stressful at all to 10 - very stressful). There were two main reasons for performing this analysis separately for women and men. Firstly, working conditions and types of jobs performed by women and men differ in the study population, an secondly, women have a tendency to overrate their symptoms, thus usually obtain higher scores in self-reported measures of health status [25]. 
The pattern of the obtained results seems to be interesting. In the case of somatic health, complementary fit was a predictor of the number of somatic diseases both in men and women. The better complementary fit, the fewer diseases the respondents suffered from. It means that congruence between employee's needs and organizational supplies or employee's expectations and organizational resources should be considered as a condition which protects the health of an employee. Certainly, one cannot ignore the fact that in the present study only a fragment of the reality is analyzed. The classical risk factors for somatic health such as e.g. diet, physical activity, health behaviors or hereditary factors were not included into the analysis, so it is quite possible that after controlling for those variables, the effects found would be reduced or even become insignificant. Nevertheless, the results indicate the importance of complementary fit to the organization as a condition of maintaining workers' health.

Complementary fit was also an important predictor of the mental health status of women as well as identification with organization. However, it is worth noting that contrary to complementary fit, stronger identification with the employing organization has adverse effect on women's mental health. This last result is contradictory to theoretical considerations and some empirical findings suggesting that employee's identification with organization is beneficial both for the organization and an employee [e.g. 33,34]. In case of our study, it appeared that the higher level of women's identification with organization the worse their mental health status. Two questions arises in relation to these results: "Why identification with organization is important for women health and has no such meaning for men?", and "Why does stronger identification with organization result in deterioration of their mental health?" To address these questions, one should have an insight into the research on gender differences affecting people's behavior.

It is worth underlining that men and women differ in the type of outcome they value. Women are more relationship-oriented and motivated by it, while men are mostly motivated by competition and status [35,36]. When we consider identification with organization as sharing the same characteristics and values, which strengthens social bounds [37] and fosters important relationships, it becomes obvious that in women, who have a stronger tendency to build and care for satisfactory relationships at work than men do, the sense of community given by identification with organization is important for their health. If identification with organization is too strong or, as it was called by Ashforth [38], overidentification appears, it may produce negative outcomes. From the organizational perspective it can be: group thinking, reluctance to raise objections or lack of creativity [38]. From the individual perspective, overidentification may produce additional stress to a person. Each negative event, each problem of the organization resonates in the Self of an employee, makes separation between work life and private life more difficult to maintain, and results in emotional overload and poor well-being.

When self-assessment of general health was analyzed, it was found that different aspects of P-O fit predict that evaluation. In case of men, complementary fit serves as a significant predictor of health evaluation, while in the female group, such role is played by supplementary P-O fit. This result is in line with the assertion than for the health of women, relation-related variables are more meaningful than for men, who appreciate more tangible benefits of work.

To the authors' knowledge, the presented study is one of scarce works on the relationship between P-O fit and health. Hopefully, it will evoke a discussion on P-O fit as a condition which maintains employees' health. Such perspective may be beneficial both from the perspective of development of the theory and from the practical point of view. Employees and employers should be interested in creating proper opportunities for the development of P-O fit, as the lack of it costs the health of the employees and money of the employers. 


\section{REFERENCES}

1. Paszkowska-Rogacz A. Psychological basis of vocational choice. Warszawa: KOWEZiU; 2003 [in Polish].

2. van Harrison R. Person-environment fit and stress at work. In: Cooper CL, Payne R, editors. Stress at work. Warszawa: PWN; 1987. p. 260-305 [in Polish].

3. Dawis RV, Lofquist LH, Weiss D.J. A theory of work adjustment: A revision. Minnesota Stud Vocat Rehab 1968;23:1-14.

4. Verquer ML, Beehr TA, Wagner SH. A meta-analysis of relations between person-organization fit and work attitudes. J Vocat Behav 2003;63(3):473-89.

5. Hoffman BJ, Woehr DJ. A quantitative review of the relationship between person-organization fit and behavioral outcomes. J Vocat Behav 2006;68(3):389-99.

6. Cable DM, Judge TA. Person-Organization Fit, Job Choice Decisions, and Organizational Entry. Org Behav Hum Dec Process 1996;67(3):294-311.

7. Kristof-Brown AL, Zimmerman RD, Johnson EC. Consequences of individuals' fit at work: meta-analysis of person-job, person-organization, person-group, and person-supervisor fit. Person Psychol 2005;58(2):281-342.

8. Bocchino CC, Hartman BW, Foley PF. The Relationship Between Person-Organization Congruence, Perceived Violations of the Psychological Contract, and Occupational Stress Symptoms. Consult Psychol J Practice Res 2003;55(4):203-14.

9. Pithers RT, Soden R. Person-environment fit and teacher stress. Educ Res 1999;41(1):51-61.

10. Caplan RD, Tripathi RC, Naidu RK. Subjective Past, Present, and Future Fit: Effects on Anxiety, Depression, and Other Indicators of Well-Being. J Pers Soc Psychol 1985;48(1):180-97.

11. Lachterman B, Meir EI. The impact of work setting congruence on well-being. J Career Assess 2004;12(2):150.

12. Merecz D, Andysz A. Person-Organization fit and work ability. Med Pr 2011;62(3):247-58 [in Polish].

13. Kristof AL. Person-organization fit: An integrative review of its conceptualizations, measurement, and implications. Person Psychol 1996;49(1):1-49.
14. Cable DM, Edwards JR. Complementary and supplementary fit: A theoretical and empirical integration. J Appl Psychol 2004;89(5):822-33.

15. Muchinsky PM, Monahan CJ. What is person-environment congruence? Supplementary versus complementary models of fit. J Vocat Behav 1987;31(3):268-77.

16. Turner JC. Social identification and psychological group formation. In: Tajfel H, editor. The social dimension: European developments in social psychology. Cambridge: Cambridge University Press; 1984. p. 518-38.

17. Turner JC. Some Current Issues in Research on Social Identity and Self-categorization Theories. In: Ellemers N, Spears R, Doosje B, editors. Social Identity: Context, commitment, content. Oxford, Malden: Blackwell Publishers; 1999. p. 6-34.

18. Czarnota-Bojarska J. Questionnaire to measure subjective Person-Organization fit. Psychol Eduk Spol 2006;3(2): 151-63 [in Polish].

19. Haslam SA, Jetten J, Postmes T, Haslam C. Social Identity, Health and Well Being: An Emerging Agenda for Applied Psychology. Appl Psychol 2009;58(1):1-23.

20. Dutton JE, Dukerich JM, Harquail CV. Organizational images and member identification. Admin Science Quart 1994;39(2):239-63.

21. Ashforth BE, Mael FA. Social Identity Theory and the Organization. Acad Manage J 1989;14(1):20-39.

22. Boroş S. Organizational identification: Theoretical and empirical analyses of competing conceptualizations. Cognition Brain Behav 2008;12(1):1-27.

23. Edwards MR, Peccei R. Perceived organizational support, organizational identification, and employee outcomes: Testing a simultaneous multifoci model. J Person Psychol 2010;9(1):17.

24. Czarnota-Bojarska J. Person-organization subjective fit questionnaire. Psychol Edu Spol 2006;3(2):151-63 [in Polish].

25. Makowska Z, Merecz D. Polish adaptation of David Goldberg's General Health Questionnaire GHQ-12 and GHQ-28. In: Dudek B, editor. Assessment of mental health on the basis of research with use of David Goldberg's questionnaires. 
Manual for users of GHQ-12 and GHQ-28. Łódź: Instytut Medycyny Pracy; 2001. p. 191-264 [in Polish].

26. Tuomi K, Ilmarinen J, Jahkola A, Katajarinne L, Tulkki A. Work Ability Index. Helsinki: Finnish Institute of Occupational Health; 1998.

27. Pokorski J. Work Ability Index - Polish adaptation. Kraków: Uniwersytet Jagielloński; 1998 [in Polish].

28. Edwards JR, Rothbard NP. Work and family stress and well-being: An examination of person-environment fit in the work and family domains. Org Behav Hum Dec Process 1999;77(2):85-129.

29. Edwards JR, Shipp AJ. The relationship between person-environment fit and outcomes: An integrative theoretical framework. In: Ostroff C, Judge TA, editors. Perspectives on organizational fit. San Francisco: Jossey-Bass; 2007. p. 209-58.

30. Furnham A, Schaeffer R. Person-environment fit, job satisfaction and mental health. J Occup Psychol 1984;57(4):295-307.

31. Leung A, Chaturvedi S. Linking the fits, fitting the links: Connecting different types of P-O fit to attitudinal outcomes. J Vocat Behav 2011;79:391-402.
32. Park HI, Monnot MJ, Jacob AC, Wagner SH. Moderators of the relationship between person-job fit and subjective well-being among Asian employees. Int J Stress Manag 2011;18(1):67.

33. Cole MS, Bruch H. Organizational identity strength, identification, and commitment and their relationships to turnover intention: does organizational hierarchy matter? J Organizn Behav 2006;27(5):585-605.

34. Dukerich J, Golden B, Shortell S. Beauty is in the eye of the beholder: the impact of organizational identification, identity and image on the cooperative behaviors of physicians. Admin Science Quart 2002;47:507-33.

35. Stuhlmacher AF, Walters AE. Genderdifferencesinnegotiation outcome: A meta-analysis. Person Psychol 1999;52(3):653-77.

36. Tannen D. You just don't understand: Men and women in conversation. New York: Morrow; 1990.

37. Kelman HC. Processes of opinion change. Public Opinion Quart 1961;25(1):57-78.

38. Ashforth BE, Harrison SH, Corley KG. Identification in organizations: An examination of four fundamental questions. J Manag 2008;34(3):325-74.

This work is available in Open Access model and licensed under a Creative Commons Attribution-NonCommercial 3.0 Poland License - http://creativecommons.org/ licenses/by-nc/3.0/pl/deed.en. 